\title{
O PROCESSO SUCESSÓRIO EM ORGANIZAÇÕES FAMILIARES E A EXCLUSÃO DA MULHER
}

\author{
Kátia Barbosa Macêdo \\ Universidade Católica de Goiás \\ Cássia Maria Moura Caixeta \\ Universidade Salgado de Oliveira \\ Daniela Cristina Guimarães \\ Mestre em Psicologia pela UGF \\ Goiacira Nascimento Segurado Macêdo \\ Faculdade Ávila \\ Janete Capel Hernandez \\ Universidade Salgado de Oliveira
}

RESUMO: O presente estudo aborda o processo sucessório em organizações familiares enfocando a exclusão da mulher deste processo. Trata-se de um estudo de caráter descritivo e exploratório, utilizando multicasos em organizações familiares localizadas no Estado de Goiás, por meio de entrevista semiestruturada com diretores(as), gerentes e trabalhadores(as) para coleta de dados, analisados com a técnica de análise gráfica do discurso de Lane (1985). Como resultados tem-se que, em decorrência de traços da cultura brasileira e da cultura das organizações pesquisadas, ocorre a exclusão da mulher do processo sucessório de organizações familiares, explicitada de duas formas: desconsiderando desde o início a possibilidade de promover mulheres para cargos de cúpula, ou considerando-as no início, mas descartando-as em etapas posteriores. Foi encontrado um número mínimo de diretores e gerentes do gênero feminino nas organizações pesquisadas, devendo-se salientar que os cargos diretivos e gerenciais ocupados por elas estão relacionados a funções consideradas "femininas".

PALAVRAS-CHAVE - exclusão, organização, empresa familiar

\section{THE SUCCESSORS PROCESS INTO FAMILY FIRMS AND EXCLUSION OF WOMEN}

ABSTRACT: The present study approaches succession process in family firms focusing women exclusion from this process. This is an exploratory and descriptive multicase study in family firms located in the State of Goiás, Brazil, carried out through the means of semi-structured interviews with workers from managerial and operational levels and analyzed with the application of the graphical discourse technique by Lane (1985). The results show that, due to Brazilian culture and family firms' features, women are excluded from the succession process in family firms in two ways: the promotion of women to managerial jobs is not taken into consideration since the beginning of the process, or the possibility is taken into consideration at first but it is rejected later on. In the organizations investigated it was found a low number of directors and managers of feminine gender, and it should be pointed out that these managerial positions taken by women are related to functions considered "feminine".

KEY-WORDS - exclusion, organization, family firms

INTRODUÇÃO

O presente artigo apresenta uma pesquisa realizada com o objetivo de levantar dados relativos à inclusão/exclusão da mulher no processo sucessório de organizações familiares, considerando a cultura organizacional como fator primordial para compreensão do processo. Parte do pressuposto de que a cultura organizacional reflete as- pectos da cultura da sociedade onde a organização se insere. Para tanto, está estruturado em três partes, sendo que a primeira apresenta a abordagem teórica de base para compreender cultura e cultura organizacional, gênero e organizações familiares; na segunda parte apresenta o método utilizado, sendo seguida dos resultados e conclusões. 
Macêdo, K.B.; Caixeta, C.M.M.; Guimarães, D.C.; Macêdo, G.N.S.; Hernandez, J.C.

"O processo sucessório em organizações familiares e a exclusão da mulher"

\section{CULTURA E CULTURA ORGANIZACIONAL}

Para compreender a cultura das organizações é necessário conhecer a cultura da sociedade na qual se inserem, bem como sua história, seus valores. Quando se aborda especificamente organizações familiares além desses aspectos, ainda devem ser considerados os relacionados aos valores familiares de seus fundadores.

Por cultura entende-se aqui um conjunto complexo e multidimensional de tudo o que constitui a vida em comum nos grupos sociais. É ainda um conjunto de modos de pensar, de sentir e de agir mais ou menos formalizados, os quais, tendo sido aprendidos e sendo partilhados por uma pluralidade de pessoas, servem, de maneira, ao mesmo tempo objetiva e simbólica, para integrar estas pessoas em uma coletividade que as distingue de outras.

A preocupação em levantar as características da cultura brasileira não é recente, visto que, desde a década de 1930, vêm-se desenvolvendo estudos e pesquisas com esse objetivo. Basta citar estudos desenvolvidos por Hollanda(1989), Azevedo (1958), Moog (1981), DaMatta (1997), Freitas(1997), dentre outros.

Faz-se necessário comentar que ,para efeito de apresentação, será utilizado o termo "cultura brasileira" no seu sentido genérico, referindo-se ao que se relaciona ou caracteriza o Brasil, devendo se resguardar todas as diferenças regionais de um país com dimensões continentais.

Hollanda isolou alguns fatores para interpretar o tipo nacional brasileiro, são eles: culto da personalidade; dificuldade para o cooperativismo e para a coesão social; presença de traços decorrentes de sua colonização por aventureiros; ausência de culto ao trabalho; cultura ornamental e cordialidade, presente como características marcantes. Já Azevedo apresentou como traços da psicologia do povo brasileiro: afetividade, irracionalidade e misticismo; religiosidade popular, cultivo da docilidade; sobriedade diante da riqueza; vida intelectual e literária de superfície, erudição não prática; individualismo não-criativo, atitude antisocial; atitude de tirar proveito em relação ao Estado. Moog levantou aspectos importantes da cultura brasileira: isolamento e individualismo; religiosidade mais instintiva e desordenada; sentido predatório - extrativista .

Para Damatta (1997), a cultura brasileira reflete uma sociedade sui generis, no sentido de que apresenta múltiplos eixos ideológicos, como a hierarquia e o individualismo, sem que sejam hegemônicos e competitivos, mas sim complemen- tares.

Conforme Caldas e Wood Jr. (1999) a cultura brasileira deve também ser analisada considerando-se a forma de colonização e a influência da economia escravocrata, latifundiária e de monocultura sobre ela aplicada e que se refletem em cinco traços essenciais. São eles: personalismo, ambigüidade, distância do poder, plasticidade e formalismo.

O personalismo relaciona-se à tendência a se dar mais importância às necessidades individuais, colocando em segundo plano as da comunidade; a ambigüidade se manifesta principalmente no chamado "jeitinho brasileiro", por meio do qual se pode utilizar não somente as regras estabelecidas, mas também ações que estão escritas nas entrelinhas, no subentendido das pessoas; a distância do poder refere-se à característica do brasileiro de julgar-se com direitos especiais que o eximem de sujeitar-se à lei de caráter generalizante; a plasticidade se manifesta pela forte valorização daquilo que é estrangeiro e pouca valorização do que é produzido no Brasil; o formalismo mostra que a excessiva abertura ao estrangeiro se dá somente na forma, dando origem ao comportamento social chamado "para inglês ver".

Além de autores brasileiros, a cultura brasileira também foi objeto de estudo de outros pesquisadores, dentre eles, destaca-se Hofstede (1994) , que realizou um estudo com o objetivo de caracterizar as culturas nacionais de vários países, dentre eles o Brasil. No que se refere ao Brasil, o estudo apontou traços de uma sociedade coletivista e caracterizada por uma distância de poder muito grande, orientação masculina e que busca ainda evitar a incerteza. Segundo ele, as organizações são marcadas por decisões que tendem a ser caracterizadas por uma interação social intensa, bem como por um envolvimento ativo dos dirigentes superiores, geralmente autocráticos. As relações sindicais ocorrem com pouca freqüência.

Deve-se comentar que as organizações compõem a sociedade e contribuem no processo de construção da realidade social. Desse modo, traços e aspectos da cultura brasileira se refletem na construção da cultura das organizações brasileiras.

O termo cultura organizacional é relativamente recente, surgiu na literatura de língua inglesa nos anos 1960. Para Fleury (1995)

"cultura organizacional é um conjunto de valores, expressos em elementos simbólicos e em práticas organizacionais, que em sua capacidade de ordenar, atribuir significações, cons- 
truir a identidade organizacional, tanto age como elementos de comunicação e consenso, como expressa e instrumentaliza relações de dominação" (Fleury, 1995, p. 27).

Freitas (1997), Coda (1997), Lodi (1994), Davel (2004 ) e Caldas e Wood Jr. (1999) levantaram traços e características presentes na cultura brasileira refletidos na cultura de organizações que pesquisaram.

Freitas desenvolveu um estudo com o objetivo de levantar traços brasileiros presentes nas organizações, que viriam a auxiliar no processo de análise organizacional, e levantou cinco deles como representantes mais marcantes.

$\mathrm{O}$ primeiro seria a hierarquia, que se traduz através de uma tendência à centralização do poder dentro dos grupos sociais; o segundo seria o personalismo, que se traduz através de passividade e aceitação dos grupos inferiores; o terceiro traço seria a malandragem, que se traduz através da flexibilidade e adaptabilidade como meio de navegação social e do "jeitinho"; o quarto seria o sensualismo e o quinto traço seria o do aventureiro, que se traduz em pessoas mais sonhadoras do que disciplinadas e com uma tendência à aversão ao trabalho manual ou metódico (cf. FREITAS,1997, p.44).

Em conseqüência do modo de funcionamento das organizações brasileiras, o trabalhador também desenvolveu uma forma particular de lidar com o trabalho. Lodi , a partir de uma pesquisa realizada, relatou que encontrou alguns traços do tipo social do brasileiro como trabalhador :

“... Alguns traços do tipo social do brasileiro que ajudam a compreendêlo trabalhando são: bondade e hospitalidade; culto da personalidade; dificuldade de obediência; falta de coesão social; aventura e imprevidência; falta de culto ao trabalho; falta de controle e acompanhamento; cultura ornamental, cordialidade, afetividade e irracionalidade; falta de objetividade; religiosidade intimista, docilidade e resignação; sobriedade diante da riqueza; individualismo e respeito pelas chefias "carismáticas." (LODI, 1994 p. 123)”.

Coda (1997) levantou em suas pesquisas a dificuldade dos gerentes e chefes desenvolverem uma identidade coerente com seu discurso, tam- bém detectada em um estudo realizado por Peter Spink (1997), em que ficou claro o distanciamento entre o discurso adotado e a prática.

Assim, pode-se afirmar que a cultura organizacional tanto constitui como é constituída por elementos da cultura nacional. É socialmente constituída e preservada pelo grupo de pessoas que, juntas, formam e mantêm a organização utilizando um discurso ideológico, visando a sua perpetuação.

\section{CULTURA DE ORGANIZAÇÕES FAMILIARES E O PROCESSO SUCESSÓRIO}

Vidigal (1996) comenta que as organizações familiares representam 99\% das organizações não estatais brasileiras. Elas representam a possibilidade de maior absorção de mão-de-obra e geração de empregos; são elas as responsáveis pela sustentação da economia e aquecimento do mercado e são elas também as mais afetadas pela globalização, segundo Lanzana (1999).

O conceito de organização familiar adotado no presente estudo é o proposto por Lanzana "aquela em que um ou mais membros de uma família exerce considerável controle administrativo sobre a empresa, por possuir parcela expressiva da propriedade do capital. Assim, existe estreita ou considerável relação entre propriedade e controle, sendo que o controle é exercido justamente com base na "propriedade". (LANZANA,1999,p. 33)

Essa definição explicita um pré-requisito para a existência da organização familiar, que é a necessidade de um grau mínimo de concentração da propriedade do capital nas mãos de uma família, o suficiente para que esta tenha legitimidade para interferir no controle administrativo.

Macêdo (2001) levantou estudos que visavam caracterizar a cultura de organizações familiares no Brasil, e verificou que alguns pontos surgiram de um modo coincidente com os resultados de suas pesquisas nos trabalhos de Secco (1980), Lodi (1993 e 1994), Bernhoeft (1989) e Vidigal (1996). Dentre eles, pode-se citar:

1- Há uma super valorização de relações afetivas em detrimento de vínculos organizacionais, em que é freqüente a valorização da confiança mútua, independente de vínculos familiares.

2- Há uma grande valorização da antigüidade, considerada como um atributo que supera a exigência de eficácia ou competência;

3- Há uma exigência de dedicação, postura de austeridade e expectativa de alta fidelidade 
Macêdo, K.B.; Caixeta, C.M.M.; Guimarães, D.C.; Macêdo, G.N.S.; Hernandez, J.C.

"O processo sucessório em organizações familiares e a exclusão da mulher"

em relação à organização;

4- É comum prevalecer ou supervalorizar aspectos emocionais quando decisões têm de ser tomadas.;

5- O autoritarismo e o paternalismo estão presentes nas relações das chefias com seus subordinados;

6- Há preferência pela comunicação verbal e pelos contatos pessoais;

7- Há a presença de posturas centralizadoras, autoritárias e, muitas vezes, paternalistas nos dirigentes em relação a seus subordinados;

8- O processo decisório nas organizações brasileiras tende a ser centralizado, residindo no chefe à última instância para a tomada de decisões ;

9- O processo decisório do brasileiro tende para um padrão mais espontâneo e improvisado e por impulso;

10- A provisão de cargos, as promoções e premiações geralmente observam critérios de confiança, lealdade e antigüidade dos trabalhadores, em detrimento de sua produtividade ou da qualidade do serviço prestado.

Talvez o aspecto mais distintivo da organização familiar seja o modo de lidar com o processo de sucessão. Esse ponto é tão importante que a maioria dos autores que estudam e pesquisam o tema privilegiam esse aspecto em suas publicações. Pode-se citar Lodi(1993 e 1994), Vidigal(1996), Bernhoeft(1989), Martins(1999) e Lanzana(1999).

Para Vidigal (1999), a situação do processo sucessório na organização no Brasil é o resultado de uma evolução da própria história da sociedade brasileira. Para ele, a decisão das famílias em substituir o sistema de primogenitura pelo sistema de divisão de herança foi um dos responsáveis pelo desmembramento das propriedades ou do controle acionário das organizações, o que gerou a fragmentação, decadência e morte da grande maioria das organizações familiares.

Ao comentar sobre a sucessão familiar, Bernhoeft (1989) comenta que ela possui seis pontos focais: o(a) sucedido(a), o(a) sucessor(a), a organização, a família, o mercado e a comunidade. Cada um deles deve ser considerado e analisado durante a preparação e o acompanhamento do processo sucessório.

Para ele, o sucedido geralmente é uma pessoa muito importante, tanto no âmbito organizacional quanto no círculo familiar. Seu estilo de vida, sua imagem na organização seu relacionamento com a comunidade externa são refletidos pelas suas ações.

Nas organizações familiares o mais comum é que o sucessor seja um membro da família, geralmente do sexo masculino, e ai já está previsto o início de um conflito familiar. Quem, dentre os inúmeros membros da família será escolhido e preparado para ser o sucessor? Quais os critérios serão utilizados para esta tarefa?

Em relação ao sucessor, Bernhoeft argumenta que devem ser considerados o seu interesse pessoal, o relacionamento com o sucedido, sua ocupação no espaço familiar e no espaço organizacional.

Quando um membro da família é escolhido para ser o(a) sucessor(a), toda a dinâmica dessa família é afetada, uma vez que este(a) "escolhido(a)" passará a ter um papel diferente também dentro da dinâmica familiar.

O trabalho direcionado para o terceiro fator, qual seja a organização em si, aborda a família organizacional, desse modo, o levantamento da interferência da família na organização deve ser realizado, visando à preparação do processo sucessório.

Para Bernhoeft, o quarto fator refere-se à estrutura familiar e deve considerar o histórico da família; interesses e motivações; verificar se há pessoas da família envolvidas em outros negócios.

Outros fatores a serem considerados são o mercado e a comunidade em que a organização está inserida. Aspectos como o perfil dos clientes, dos fornecedores e da concorrência, além de dados relacionados ao campo de atuação da organização, devem ser identificados, uma vez que direcionarão todo o trabalho de desenvolvimento do sucessor , bem como do planejamento estratégico da mesma.

A preparação para a sucessão segue alguns passos que incluem desde a preocupação com o(a) sucedido(a), que deverá descobrir outras atividades para desempenhar fora do espaço organizacional, o treinamento e o desenvolvimento de habilidades do(a) sucessor(a), bem como sua inclusão na cúpula da organização (caso ainda não esteja fazendo parte dela), o planejamento dos novos rumos que a organização deverá seguir, até o acompanhamento das interferências destas mudanças em nível organizacional e familiar.

Lodi justifica a importância de um processo sucessório bem conduzido, e aponta-o como fator primordial para a continuidade das organizações familiares, e comenta:

"O rodízio de poder tem ocorrido todo o tempo, pois no universo da estatística familiar há sempre um certo percentual de dirigentes se afastando, se considerarmos 25 anos o tempo de 
cada geração. Hoje fundadores de empresas do pós-guerra estão passando. Mas logo mais também serão os empresários que cresceram com a Revolução de 1964. E mais adiante as gerações mais novas, como aquela que fundou a indústria de informática em nosso país. Algumas empresas familiares passarão à profissionalização total, ou seja, ao afastamento dos familiares para o conselho ou mais além. Outras sofrerão cisões como solução para a incompatibilidade entre os parentes do fundador. Outras terão o poder acionário concentrado em apenas um ramo da família. Um bom número de empresas será vendido pelos herdeiros como forma de superar suas divergências. Haverá empresas que passarão ao controle de fundações devido à falta de herdeiros." (LODI, 1994,p. 26).

Assim, pode-se afirmar que o processo sucessório em organizações familiares se constitui em um eixo fundamental para sua compreensão e como fator preponderante para a continuidade da organização, visto que em muitos casos, várias organizações familiares são desfeitas durante ou logo após um processo sucessório mal conduzido.

\section{CULTURA DE ORGANIZAÇÕES BRASILEIRAS E AS RELAÇÕES DE GÊNERO}

De acordo com Morgan (1996), muitas organizações constroem sua cultura, estrutura, normas, objetivos e procedimentos baseados em alguns valores, geralmente de seus fundadores ou reproduzindo valores da sociedade na qual se insere. No que se refere às relações de gênero, muitas vezes privilegiam um sexo em detrimento do outro, favorecendo a manutenção da cultura patriarcal.

A palavra gênero é resultado de uma construção social histórica. As relações de gênero são relações de poder que se constroem constantemente ao longo da história e no dia-a-dia entre homens e mulheres, mulheres e mulheres, homens e homens.

Gênero, enquanto uma categoria útil para a análise, é de uso recente, cujo valor heurístico permite uma abordagem das dimensões sócio-econômicas e das relações existentes entre os seres humanos. Esta categoria de análise, ainda em construção, tem o propósito de desnaturalizar as categorias homem e mulher, no sentido de indicar uma rejeição ao determinismo biológico. Segundo Grossi
(2000), o campo de estudos que hoje, no Brasil, denomina-se de gênero ou relações de gênero surgiu nos anos 1970/1980, em torno da problemática da condição feminina.

Nas sociedades ocidentais, como a brasileira, assinala Bruschini (1999), predominam relações de gênero assimétricas e hierárquicas, que se expressam em posições desiguais ocupadas pelas pessoas de um e outro sexo tanto na esfera da produção quanto no âmbito privado das relações familiares. Apesar das transformações do mundo moderno, pode-se constatar que, ainda hoje, destina-se às mulheres, sobretudo, as atividades reprodutivas e os cuidados com a casa e os membros da família, enquanto aos homens cabe o papel de provedor desse grupo.

As relações de dominação entre as classes sociais, que são regidas pela ideologia, se reproduzem via instituições e organizações, as quais prescrevem os papéis e determinam as relações sociais entre os membros de uma dada sociedade.

Para Spink (1997), a ideologia é produto social, identificável em sistemas de símbolos como uma estrutura de significação mobilizada para legitimar os interesses de grupos hegemônicos e pode ser tratada como uma característica constante da dialética da vida social. Thompson (1995) afirma que ideologia, enquanto prática, não deve ser entendida como uma prática qualquer; deve ser uma prática que serve para criar ou manter relações assimétricas, desiguais e injustas.

Assim sendo, nenhuma idéia, diz Guareschi, mesmo que seja da classe dominante é, por definição, mistificadora ou falsa; agora se ela de fato "ilude e esconde a realidade, então se diz que é uma ideologia" (GUARESCHI, 2002, p. 94). A ideologia se apresenta como "algo abstrato ou impraticável; como algo ilusório ou errôneo, expressando interesses dominantes e como que sustentando relações de dominação" (GUARESCHI, 2002, p. 91).

Para Bruschini e Rosemberg (1982), a ideologia dentro das organizações, no que se refere à questão de gênero, encarregou-se de transformar a rígida divisão sexual do trabalho em uma divisão natural, própria à biologia de cada sexo, contribuindo para justificar o fato de que a mulher cumpra ordens dadas pelos homens.

Segundo Louro(1998) enfatizar o aspecto social não significa necessariamente negar que o gênero se constitui em corpos sexuados. Isto valoriza intencionalmente a importância da construção social e histórica produzida sobre as características biológicas. Para ela, "as justificativas para as desigualdades precisariam ser buscadas não 
Macêdo, K.B.; Caixeta, C.M.M.; Guimarães, D.C.; Macêdo, G.N.S.; Hernandez, J.C.

"O processo sucessório em organizações familiares e a exclusão da mulher"

nas diferenças biológicas, mas sim nos arranjos sociais, na história, nas condições de acesso aos recursos da sociedade, nas formas de representação". Louro, 1998,p.(22)

Assim, algumas organizações tendem a segmentar as estruturas de oportunidades, mediadas pela ideologia, de modo a favorecer aos homens chegarem a posições de prestígio e poder, mais fácil e rapidamente que as mulheres, ou seja, a exclusão da mulher principalmente no que tange a assumir cargos diretivos.

Segundo Bruschini, "apesar da conquista de novos espaços, no entanto, as mulheres ainda são discriminadas" (BRUSCHINI, 1999, p. 75). Elas continuam encontrando maior dificuldade para ocupar cargos de chefia e ganham menos do que seus colegas em quase todas as ocupações.

Pode-se observar que alguns traços da cultura brasileira, como o patriarcalismo, políticas de privilégios e autoritarismo estão presentes também na cultura das organizações. Interferem na construção de políticas de pessoal, principalmente quando contribuem para a perpetuação de um discurso ideológico que reafirma a divisão sexual do trabalho, legitimando assim a exclusão da mulher de processos de desenvolvimento profissional.

Faz-se necessário apresentar um conceito de exclusão proposto por Sawaia(1999)

“... Em síntese, a exclusão é processo complexo e multifacetado, uma configuração de dimensões materiais, políticas, relacionais e subjetivas. È um processo sutil e dialético, pois só existe em relação à inclusão como parte constitutiva dela. Não é uma coisa ou um estado, é processo que envolve o homem por inteiro e suas relações com os outros. Não tem uma única forma e não é uma falha do sistema, devendo ser combatida como algo que perturba a ordem social, ao contrário, ele é produto do funcionamento do sistema". (SAWAIA, 1999, p.9)

Assim, deve-se ressaltar que o processo de exclusão não é individual, mas é um processo social que inclui discriminação, subalternidade, desigualdade, discriminação, falta de acesso.

Jodelet(1999) afirma que a exclusão induz sempre uma organização específica de relações interpessoais ou entre grupos que se traduz em segregação, afastamento , marginalização, discriminação, fechamento do acesso a recursos, e lembra ainda que ela sempre se instala em uma interação entre pessoas ou grupos.

No caso das organizações, a cultura, valo- res, normas adotadas muitas vezes se colocam a serviço da manutenção do status quo.

Como já foi dito anteriormente, o objetivo da presente pesquisa foi o de levantar dados acerca de como o processo de sucessão em organizações familiares ocorre, enfocando especificamente a dialética da inclusão/exclusão da mulher no referido processo, considerando a cultura organizacional como fator constituinte do referido processo.

MÉTODO

Trata-se de uma pesquisa de caráter descritivo e exploratório, que utilizou multicasos. O objetivo era verificar como ocorre a dialética da inclusão/exclusão das mulheres no processo sucessório das organizações familiares pesquisadas.

Foram pesquisadas cinco organizações familiares, todas localizadas no Estado de Goiás. Duas atuam na área de comércio/serviços, uma na área de indústria, e duas no setor de serviços. Quanto ao porte das organizações, uma é considerada de grande porte, e as outras quatro de médio porte. Todas empregam trabalhadores de ambos os sexos. Todas já haviam passado por pelo menos um processo sucessório antes da coleta de dados.

Como instrumento de coleta de dados, foi utilizada entrevista semi-estruturada, e seu roteiro foi composto por três categorias, sendo: 1- identificação; 2- relato sobre o(s) processo(s) sucessório(s) ocorrido(s) na organização onde atua e 3- relato sobre como se deu a inclusão/exclusão da mulher no(s) processo(s) sucessório(s) relatados(s).

A composição da amostra foi intencional e visou levantar dados com vinte trabalhadores, sendo quatro participantes de cada uma das cinco organizações. A amostra considerou o nível hierárquico (diretivo, gerencial e operacional) e o gênero dos sujeitos. Dos vinte trabalhadores participantes, 11 eram do sexo masculino e 9 do sexo feminino, a idade variou entre 32 a 60 anos; 15 eram casados e o grau de escolaridade predominante era superior completo.

As entrevistas foram transcritas e analisadas pela técnica de análise gráfica do discurso de Lane (1985).

\section{RESULTADOS}

Serão apresentados os resultados de cada organização separadamente, considerando alguns dados de sua caracterização enquanto organização, um breve relato acerca do(s) processo(s) sucessório(s) ocorrido(s) até a coleta de dados, e ainda uma breve exposição dos relatos acerca da 
questão da inclusão/exclusão das mulheres no referido processo.

\section{O processo sucessório na organização 1}

A organização atua na área de transportes, é de médio porte já havia passado por dois processos sucessórios na época da coleta de dados, sendo que nas duas vezes em que ocorreu houveram mudanças no quadro de sócios.

Ao relatarem sobre o processo de sucessão, afirmaram que os critérios que nortearam a escolha dos sucessores foram: ser filho do dono, preferencialmente com dinheiro disponível para aplicação na sociedade; ter vivência ou experiência de trabalho na organização; ser homem para o cargo de direção.

Nos dois processos de sucessão, houve conflitos para a escolha dos sucessores, e como não chegaram a um consenso, os sócios decidiram desfazer a sociedade, motivo que gerou mudanças no quadro de sócios.

Ao serem perguntados sobre a inclusão/ exclusão da mulher no processo, responderam que as mulheres da família não tinham dinheiro para entrar na sociedade, e ainda que não tinham perfil para assumir cargos de direção.

"na área de transportes o perfil dos clientes e das atividades exige que sejam homens para negociar e decidir, com mulher fica difícil..." S3O1

Em nenhuma composição de diretoria durante as três gestões havia uma mulher ocupando cargo de diretoria ou gerência. Mesmo havendo uma das filhas dos donos com formação superior na área de administração e com experiência dentro da organização, ela ocupava o cargo de assessora da diretoria, e desenvolvia tarefas de negociação, atendimento a clientes, mas não de decisões. Ao ser perguntada sobre a escolha do sucessor, ela relatou que:

"O meu irmão mesmo não tendo experiência eles engoliram, eu não, e isso é apenas pelo fato deu ser mulher. Eles deram a chance para ele, mesmo sem ter conhecimento suficiente na época, e me discriminaram, tiraram o tapete dos meus pés, tiraram a minha oportunidade. Hoje ele esta no cargo que eu estava sendo preparada. O fato deu ser mulher, eles concluíram que eu não era competente para assumir essa responsabilidade e esse cargo de chefia. Aqui, os homens têm sempre mais oportunidades, lembrando bem, para os cargos de chefia e decisão. O que parece é que aqui as mulheres só servem para trabalhar na área operacional, ou para eles assediarem elas". S4O1

Percebe-se pelos relatos a existência de traços da cultura patriarcal, refletidos na cultura organizacional, em forma de critérios para definição dos sucessores, e ainda a construção de um discurso ideológico para justificar e naturalizar a exclusão das filhas mulheres desse processo sucessório. Percebe-se que houve uma diferenciação no tratamento entre filhos de uma mesma família, embasada no gênero dos filhos. Apesar do discurso ideológico apontar para características do mercado de atuação, no discurso da filha esclarece que a exclusão se fundamenta no fato de ela ser mulher.

\section{O processo sucessório na organização 2}

A organização 2 atua no ramo industrial, é de grande porte e emprega preferencialmente mão-de-obra feminina que fica concentrada na área operacional.

Na época da coleta de dados já havia passado por três processos sucessórios, também com mudança no quadro de sócios.

Ao relatarem sobre os critérios para a escolha dos sucessores, os critérios citados foram: ser membro da família; ter experiência na organização e entender do negócio. Nesta organização também ocorreu dissolução da sociedade inicial durante o processo sucessório, decorrente de conflitos na escolha dos sucessores.

Até a terceira sucessão, não havia nenhuma mulher ocupando cargos na diretoria, realidade que mudou quando um dos sócios faleceu e sua esposa assumiu seu posto.

Ao relatarem sua impressão sobre o fato, alguns trechos de entrevistas chamam a atenção para a dificuldade que a sócia enfrentou e continua enfrentando pelo fato de ter assumido um cargo da diretoria.

O relato da diretora deixa claro que há diferenças no tratamento dispensado para homens e mulheres, dentro da organização, e, ao que tudo indica, esse tratamento diferenciado em decorrência do gênero é um traço característico da cultura desta organização.

"Aqui dentro, por exemplo, eles respeitam muito mais um homem do que uma mulher. É tanto que eu e minha mãe, a diretora, nós sofremos discriminações aqui dentro por sermos mulher. Até hoje a minha mãe não é engolida aqui dentro porque ela é 
Macêdo, K.B.; Caixeta, C.M.M.; Guimarães, D.C.; Macêdo, G.N.S.; Hernandez, J.C.

"O processo sucessório em organizações familiares e a exclusão da mulher"

mulher, entendeu, e comigo é a mes-

ma coisa. ... aqui na empresa, o que prevalece são os desejos e decisões dos homens. Embora a minha mãe tenha $33 \%$ da empresa, é como se ela não tivesse, porque são os seus sócios que tem o poder nas mãos. Literalmente, aqui na empresa a mulher não tem poder de decisão". (S1)2).

Neste trecho, ela relata traços de uma cultura organizacional com traços "machistas", que dificulta a atuação profissional da mulher em cargos diretivos, e ainda relata a ocorrência de formação de alianças e coalizões para excluí-la e seus projetos também.

"Eles, nem meu pai, nem o marido me deram chances deu caminhar sozinha. Vim parar em uma sociedade machista, os sócios, que não querem a presença da mulher até hoje, é difícil, mas estamos aqui segurando as pontas". (S2)2).

"quando é para alguma votação, alguma outra coisa assim, eu sempre perco. Perco, perco, porque eles se unem, então é dois contra um. Ou é dois contra um, ou é quatro contra dois, porque no conselho são os dois e os dois filhos, eu e meu filho". (S2)2).

Essa situação relatada é percebida por outros gerentes e trabalhadores da área operacional. Nos trechos abaixo, fica clara a percepção do conflito por parte de outros membros da organização. A pesar de um discurso ideológico por parte dos outros diretores, e de uma administração simbólica com o objetivo de minimizar a percepção dos conflitos, eles emergem e os traços da cultura organizacional excludente, patriarcal e de privilégios contribuem para que o desenvolvimento das atividades da organização seja comprometido.

"Ela lida constantemente com cinco contra ela, e eu não estou dizendo que é demérito dela não, é pela estrutura machista da organização". (S3)2).

"Eu acho que é pelo fato de ser dirigida por uma mulher. É a única mulher. Acho que os homens fazem de tudo para enfraquecê-la. E acho que acabam conseguindo. É pura discriminação, tenho certeza se fosse um homem, como já foi, as coisas seriam diferen- tes. Aqui, o homem sim, tem o seu lugar garantido ao sol. Aos homens tudo, e as mulheres, aquilo que eles não querem, ou acham insignificantes e sem valor". (S1O2).

"Eles decidem (...), as famílias (...), os homens das famílias, eles decidem, pois ao todo, no corpo diretivo, as famílias, são cinco homens e uma mulher, então é claro que quem decide são os homens, a mulher é missa de corpo presente, o que ela fala e um risco na água, tem a mesma duração e importância". (S302)

Os outros diretores, ao serem perguntados sobre a inclusão/exclusão das mulheres para a preparação da próxima sucessão, responderam:

"Nada é impossível, mas acho pouco provável, pois os sucessores são todos homens".(S1O2).

Assim, percebe-se que mesmo quando uma mulher assumiu um cargo de diretoria nessa organização, fato esse decorrente de seu direito legítimo enquanto proprietária, ainda assim ela enfrentou e continua enfrentando dificuldades até mesmo entre seus colegas diretores em decorrência do de ser mulher. Nesta organização o processo de exclusão da mulher ocorre de forma evidente, evidenciando uma cultura organizacional que privilegia os homens em cargos diretivos, e delega para as mulheres apenas os cargos da área operacional, por ser "naturalmente" ligadas a funções femininas.

\section{O processo sucessório na organização 3}

A organização 3 é uma organização do segmento hoteleiro de médio porte.

$\mathrm{Na}$ época da coleta de dados, havia ocorrido apenas um processo sucessório. Ao relatarem sobre o processo sucessório, disseram que o fundador, como forma de preparar suas herdeiras para assumir totalmente a direção da organização, delegou a duas de suas filhas e um genro a direção da mesma. Os critérios para sucessão eram: ser membros da família e conhecer o negócio. Uma das filhas se desligou da diretoria por motivos pessoais; continuando a outra filha e o cunhado e um sobrinho na função de gerente geral. A divisão de tarefas foi estruturada considerando as funções "masculinas e femininas", ou seja, decorrentes do processo de naturalização que partem da divisão sexual do trabalho.

Ao ser perguntado sobre os motivos para a divisão dos cargos dos diretores, o fundador res- 
pondeu:

"O X(cunhado) é o diretor administrativo financeiro, cuida do dinheiro da família" (SD1)

Essa função é coerente com as consideradas "masculinas", o papel de provedor, onde cabe ao homem a função de administrar os bens e o dinheiro da família. Um discurso ideológico que naturaliza a divisão sexual do trabalho.

“... a Y(filha) é Diretora de alimentos e bebidas, e administra tudo que se relaciona à alimentação dos hóspedes e funcionários..." (SD1)

Essa função também parece coerente com o modelo familiar, cujo papel da mulher está ligado a questões domésticas, principalmente a alimentação.

Em relação à divisão de tarefas, percebese nesta organização que, mesmo uma filha ocupando um cargo de diretoria, as funções de dita diretoria se relaciona a funções "naturalmente" femininas, reproduzindo a divisão do trabalho presente na cultura brasileira, considerando o gênero.

A propriedade do capital, ou seja, o fato de ser sócia, significa que sua opinião tem prevalência nas decisões. O relato de um dos diretores deixa isso claro.

“... Quando não chegamos a um acor-

do, sua posição prevalece, pois é a fi-

lha do dono...." (S1O3)

Percebe-se que a cultura desta organização reflete traços da sociedade brasileira, em especial quanto aos traços de autoritarismo, busca pelo poder e busca de resolução de conflitos. Assim, fica evidente que nesta organização familiar o fato de ser dono do capital é condição sine qua non para decisões, conforme Lanzana já tinha afirmado.

\section{O processo sucessório na organização 4}

Trata-se de uma organização familiar privada de médio porte, e que atua no ramo comercial de caminhões e prestação de serviços de oficina. Em 28 anos de existência passou por um processo sucessório que acarretou mudanças no quadro de sócios.

Ao relatarem sobre o processo sucessório, declararam que os critérios para a escolha dos sucessores eram: ser membros da família (sócios); ter experiência na empresa.

Da sua fundação até o momento da coleta de dados a organização tinha passado por um processo sucessório, ocorrido cinco anos antes.

A Diretora administrativa-financeira (fi- lha), na época da coleta de dados, tinha 40 anos, era formada em inglês e economia, ganhou espaço na diretoria após um longo tempo de trabalho demonstrando sua competência.

“...Quando meu pai mudou pra essa sede e precisaria de um gerente administrativo, eu me dispus a vir trabalhar com ele. Ele até foi um pouco resistente porque ele achava que esta questão familiar é um pouco complicada e existe uma resistência do próprio colaborador em aceitar filho de dono da empresa, já tinha meu irmão aqui. [...] devagarzinho eu fui galgando, e hoje eu já assumo a parte administrativa e a financeira".(S2O4)

Por outro lado, o filho parece não ter encontrado tanta resistência por parte do pai, como no depoimento a seguir.

“...Então a gente, no começo era só eu, então passou, um dos filhos passou a trabalhar comigo e estamos ganhando o mercado." (S3O4)

Além dos filhos de um dos sócios assumirem cargos diretivos, uma terceira pessoa também participou do processo sucessório, porém de um modo diferente.

Este aconteceu em decorrência do falecimento de um dos sócios proprietários, que era dono de $50 \%$ das ações, não pertencia à mesma família e que não ocupava cargo de diretoria na época, apenas acompanhando os relatórios e balancetes da cidade onde residia. Sua cunhada chegou na organização e, como não existia um cargo disponível, ela passou por vários setores até se tornar diretora do Departamento de Recursos Humanos, que até então era denominado de Departamento de Pessoal e desenvolvia basicamente atividades como folha de pagamento, admissão e demissão de pessoal.

A diretora assumiu o cargo e, segundo ela mesma e outros diretores e funcionários,

“... foi uma adaptação difícil..." S2O4)

“...Ela entrou depois de algum tempo que eu já estava aqui, a gente não sabia como colocá-la na empresa, ela tinha curso de jornalismo, é advogada e nunca tinha trabalhado nessa área. Ela passou por um período na administração, não deu muito certo, porque ela não é legal pra lidar com número com conta e essas coisas. Até achar o espaço dela que é no RH. Então, na parte que eu não tenho tanta 
Macêdo, K.B.; Caixeta, C.M.M.; Guimarães, D.C.; Macêdo, G.N.S.; Hernandez, J.C.

"O processo sucessório em organizações familiares e a exclusão da mulher"

sensibilidade, tanto tempo, tanta pa-

ciência é que ela se encaixa." (S1O4)

“...No princípio eu achei que ela não tinha experiência pra comandar uma empresa igual a essa. Ela demonstrava ser uma pessoa amiga, na época, mas eu tinha minhas dúvidas. Pelo jeito dela ser, o jeito de querer comanda [...] Então ela chegou e mexeu em um setor, mexeu em outro, mexeu em outro. Algumas coisas davam certas, outras davam errado." (S1O4).

Com a entrada da nova diretora, o Departamento de Pessoal ampliou suas atividades, e criou um projeto de Qualidade de Vida no Trabalho, e ainda estruturou os projetos de Qualidade Total e a ISO 9004. Alguns relatos de outros diretores e gerentes sobre a atuação da diretora:

“...faz um trabalho muito bonito, na periferia, não ficou só na nossa escola de computação.Se não tem trabalho nas escolas, tem trabalho nas estradas, tem trabalho em presídios, tem trabalho com crianças. Um trabalho bonito aí, na prevenção da AIDS." (S4)4)

“...É uma parte mais humanitária da diretora, sabe! Ela é muito preocupada com... com as pessoas carentes, deficientes, pobres né! E ela sempre contribuiu!" (S2O4)

Novamente fica claro que a absorção de mulheres em cargos de diretoria, principalmente, se configura como um processo muito mais rigoroso do que para os homens, de uma mesma família, mesmo se as filhas possuem formação mais específica e experiência na organização, o que reflete uma cultura com base patriarcal de poder. Talvez isso se deve pelo fato de cargos de diretoria representarem poder, e as figuras de poder na sociedade brasileira geralmente estão associadas ao sexo masculino.

È importante salientar que novamente a área para onde são encaminhadas mulheres é a de Recursos Humanos, e que as funções ligadas a ela se relacionam com o papel feminino de cuidado, ou seja, em caso de absorção de mulheres na diretoria, parece haver uma tendência de que sejam locadas no departamento de recursos humanos, desempenhando tarefas ligadas a "funções femininas".

5. O processo sucessório na organização 5
A organização 5 atua no ramo comercial e de prestação de serviços e tem médio porte. Em 40 anos de existência passou por mudança no quadro de sócios decorrente de um processo sucessório, e era dirigida na época da coleta de dados pelos filhos do fundador, sendo duas mulheres e dois homens.

Ao relatarem sobre o processo sucessório, afirmaram que os critérios para sucessão foram ser filhos do sócio. Quando houve o processo sucessório, um dos donos comprou as ações do outro sócio e convidou seus três filhos para assumir a direção da organização. Um dos filhos homens assumiu a diretoria administrativa e o outro a diretoria financeira, uma das filhas assumiu a diretoria de recursos humanos e a outra a diretoria comercial.

Segundo relatos, os filhos homens estiveram presentes desde criança na organização, e as filhas só entraram na mesma quando assumiram os cargos de diretoria.

"Desde de moleques a gente sempre via os meninos na empresa. Nas festas eles participavam. Quando eram adolescentes trabalharam em vários departamentos da empresa... As meninas eu nunca vi." (S1O5)

Ao serem perguntados sobre a inclusão/ exclusão da mulher, ficou claro que o critério adotado foi o de ser filhos do dono (sócio), e os quatro filhos assumiram cargos de direção, independente do sexo e da experiência que tinham na organização. A cultura dessa organização, no que se refere aos aspectos de gênero é inclusiva e não discriminatória.

Nesta organização a mulher ocupa de fato posições de poder, podendo ser considerada uma exceção no universo pesquisado.

\section{DISCUSSÃO}

Pode-se afirmar que os objetivos do presente estudo foram alcançados, e que o método utilizado foi adequado. Os dados levantados demonstram que a cultura organizacional tende a refletir traços da cultura da sociedade onde se insere. Em algumas, percebe-se que a cultura organizacional reflete a cultura patriarcal e excludente da mulher na cultura brasileira, enquanto que em outras ocorre uma superação desse traço em direção a uma cultura mais inclusiva em relação à divisão de trabalho por gênero. A segunda tendência também reflete mudanças na sociedade brasileira, pois, segundo dados do IBGE, mais da metade das famílias brasileiras dependem economicamente para sua sobrevivência do trabalho 
da mulher, o que põe por terra a idéia do homem como provedor, os dados indicam mudanças nessas relações sociais.

Conforme citado anteriormente, no estudo de Hofstede, um dos traços da cultura brasileira era a orientação masculina da sociedade, significando traços de competitividade, individualismo e pouca ou nenhuma orientação para aspectos de alteridade, aspectos que puderam ser evidenciados no presente estudo em algumas das organizações pesquisadas.

Em relação ao processo sucessório, percebe-se que o fato de pertencer à família dos donos é fator primordial para a escolha dos sucessores em um primeiro momento; que o gênero desses familiares também é fundamental, em um segundo momento, além de algumas das organizações pesquisadas também adotarem como critério para a escolha do sucessor a experiência ou vivência do negócio. Assim, o que caracteriza familiar primordialmente, que é o fato de uma família possuir a maioria das ações, o que a legitima para dirigir a empresa se aplica aos casos estudados, e corrobora o conceito de Lanzana.

Com relação à inclusão/exclusão da mulher no processo de sucessão familiar, pode-se perceber que, na maioria das organizações estudadas, ocorreu exclusão da mulher na escolha dos sucessores. Essa exclusão ocorreu de várias formas, sendo que em algumas ela foi declarada, enquanto em outras, ela foi dissimulada. Essa dissimulação foi realizada ou considerando as mulheres como candidatas em um primeiro momento e posteriormente descartando-as, ou mesmo utilizando um discurso ideológico que naturalizava a missão e os objetivos da organização como de orientação masculina, visando justificar o porque do descarte dos nomes das candidatas mulheres na decisão final. Além dessa etapa inicial, percebe-se que a exclusão continuou ocorrendo na maioria das organizações pesquisadas, mesmo após a mulher assumir o cargo de diretoras.

Mesmo quando as filhas e esposas participam do processo sucessório, geralmente assumem funções ligadas a funções socialmente consideradas como "femininas", ocupando funções na área de Recursos Humanos, e , assim, reproduzindo a divisão sexual do trabalho da sociedade. Outras vezes, participam do processo sucessório, porém enfrentam mais dificuldades que os seus familiares do sexo masculino, inclusive no desempenho de suas funções.

As explicações para essas diferenças podem residir em culturas organizacionais que refletem aspectos da cultura brasileira, já discutidos ante- riormente, e que encontram consonância com a história da organização e com os valores da família proprietária da mesma para construir e delinear estruturas e normas organizacionais baseadas em privilégios, exclusões, patriarcalismo, etc.

Partindo do pressuposto de que cultura é aprendida, pode-se afirmar que a subordinação em que vive a mulher, de acordo com Silva (2001), é reproduzida pelo processo educativo relacionado ao fator cultural. As justificativas apresentadas para expor e fortalecer tal situação vêm da ideologia que a naturalização da divisão sexual do trabalho utiliza para explicar as diferenças no tratamento dado a homens e mulheres nas organizações. Dentre as explicações, surgem desde as razões biológicas, que apontam a condição da mulher como reprodutora como indicação de sua fragilidade, até sua destinação histórica de ser complementar do homem em todas as suas atividades. Assim, a ideologia legitima ações de exclusão da mulher no ambiente organizacional. Exclusão no sentido trabalhado por Jodelet(1999), onde sempre ocorre em interações pessoais e que se traduz em segregação, afastamento , marginalização, discriminação , fechamento do acesso a recursos, podendo ocorrer com várias nuances, mas sempre cumprindo seu papel segregador.

Vale destacar que, na sutileza do discurso ideológico produzido e mantido pela cultura, busca-se mascarar as relações de poder e dominação que se fazem presentes nessas relações. Para Silva (2001) e Farr (1991), a mulher não nasceu destinada à submissão, nem é por natureza um ser inferior. Porém, a diferença entre os sexos se converteu em desigualdade que, por sua vez, se transformou em valor cultural nas diversas sociedades. A ideologia dominante reforça e reproduz a subalternidade da mulher, passando a se apoiar nela para a sobrevivência de suas estruturas hierárquicas, patriarcais e conservadoras. Tal idéia é repassada, geração após geração, por meio de manifestações culturais que criam para a mulher uma situação de definitiva inferioridade. Cabe às mulheres, enquanto trabalhadoras, estarem atentas e divulgar fatos, quando perceber que estes fatos contribuem para a perpetuação da exclusão do acesso da mulher para seu crescimento e contribuição na construção de uma sociedade mais justa e igualitária.

Os dados do presente estudo não podem ser generalizados, uma vez que não foi objetivo deste tipo de estudo fazer generalizações, porém colaborar na construção de conhecimento do objeto estudado, bem como contribuir para o delineamento de futuras pesquisas. 
Macêdo, K.B.; Caixeta, C.M.M.; Guimarães, D.C.; Macêdo, G.N.S.; Hernandez, J.C.

"O processo sucessório em organizações familiares e a exclusão da mulher"

\section{REFERENNCIAS}

AZEVEDO, F. A cultura brasileira: introdução ao estudo da cultura no Brasil. 3. ed. São Paulo : Melhoramentos, 1958.

BERNHOEFT, R. Empresa familiar: sucessão profissionalizada ou sobrevivência comprometida. São Paulo: Nobel, 1989.

BRUSCHINI, Cristina; ROSEMBERG, Fúlvia. A Mulher e o Trabalho. In: BRUSCHINI, Cristina; ROSEMBERG, Fúlvia (orgs.). Trabalhadoras do Brasil. São Paulo: Brasiliense, 1982.

BRUSCHINI, Cristina; ROSEMBERG, Fúlvia. $M u-$ lher e Mundo do Trabalho: ponto de vista sociológico. In CALDAS, M. P.; WOOD JR., T. Transformação e realidade organizacional - uma perspectiva brasileira. São Paulo: Atlas, 1999.

CODA, R. Pesquisa de clima organizacional e gestão estratégica de recursos humanos. In: BERGAMINI, M.C. (Org.). Psicodinâmica da vida organizacional: motivação e liderança. 2. ed. São Paulo : Atlas, 1997.

DaMATTA, R . O que faz o brasil, Brasil? Rio de Janeiro : Rocco, 1997.

DAVEL, Eduardo - Aprendizado e Formação Continuada em Organizações Familiares e Intensivas em Conhecimento: A Força das Relações de Parentesco por Consideração. Anais do III Encontro de Estudos Organizacionais, Anpad:Rio de Janeiro, 2004.

FARR, Ellen; CHITIGA, Rudo. Hallo - Is Gender There? A study of gender. Awareness in the MS Programme in Zimbabwe: Mach, 1991.

FLEURY,M.T Arqueologia teórica e dilemas metodológicos dos estudos sobre cultura organizacional . In: DAVEL,E., VASCONCELOS, J.(Org.). Recursos Humanos e Subjetividade. Petrópolis: Vozes , 1995.

FREITAS, A .B . Traços brasileiros para uma análise organizacional in Cultura organizacional e Cultura brasileira. In: MOTTA, F.C.P. (Org.). Cultura organizacional e cultura brasileira . São Paulo : Atlas, 1997.

GUARESCHI, Pedrinho. Ideologia. In: JACQUES, Maria das Graças C; STREY, Marlene N; BERNARDES, Nara M.G. Psicologia Social Contem- porânea. 6a ed. Petrópolis/RJ: Vozes, 2002.

GROSSI, Mirian P. Identidade de Gênero e Sexualidade. Estudos de Gênero. Cadernos de Área, n. 9. Programa Interdisciplinar da Mulher - Estudos e Pesquisas. Goiânia: UCG, 2000.

HOFSTEDE, G. Cultures and organizations: cultural cooperation and its importance for survival. London: McGraw-Hill International, 1994.

HOLLANDA,S.B. Raízes do Brasil. Rio de Janeiro : José Olympio, 1989.

IBGE - Senso de 2000, pesquisado no site www.ibge.gov.br com acesso em 2/6/2003

JODELET,D. Os processos psicossociais da exclusão. In SAWAIA, B.B. (org.) As artimanhas da exclusão: análise psicossocial e ética da desigualdade social. Petrópolis: Vozes, 1999.

LANZANA, A ., CONSTANZI, R. As empresas familiares brasileiras diante do atual panorama econômico mundial. In: MARTINS, J. (Coord.). Empresas familiares brasileiras: perfil e perspectivas. São Paulo : Negócio Editora, 1999.

LODI, J.B. A empresa familiar. 4. ed. . São Paulo : Pioneira , 1993.(Biblioteca Pioneira de Administração e negócios.)

LODI, J.B. A ética na empresa familiar . São Paulo: Pioneira , 1994 .(Biblioteca Pioneira de Administração e Negócios.)

LOURO, Guacira L. Gênero, Sexualidade e Educação: uma perspectiva pós-estruturalista. Petrópolis/ RJ: Vozes, 1998.

MACÊDO, Kátia Barbosa. Empresa familiar Brasileira: cultura, poder e decisão. Goiânia: Editora Terra e Editora da Universidade Católica de Goiás, 2001.

MARTINS, J.G.(Coord.) et. al. Empresas familiares brasileiras: perfil e perspectivas. São Paulo: Negócio Editora, 1999.

MOOG, V. Bandeirantes e pioneiros. 13. ed.. Rio de Janeiro: Civilização Brasileira, 1981.

MORGAN, G. Imagens da organização. Tradução de Cecília Bergamini e Roberto Coda. São Paulo: Atlas, 1996. 
SAWAIA, B.B. (org.) As artimanhas da exclusão: análise psicossocial e ética da desigualdade social. Petrópolis: Vozes, 1999.

SECCO, R. O administrador organizacional e o processo decisório .Revista Executiva, Porto Alegre, v.6(24), p. 36-67, mai./ago. 1980.

SILVA A.L.; VILAS BOAS L.H.B e BRITO M.J. As Representações Sociais sobre a Mulher: percepções de gênero em uma agência bancária. Campinas/ SP: Anais do $25^{\circ}$ Encontro da ANPAD, 2001.

SPINK, P.K.. Discurso e ideologia gerencial: reflexões a partir da experiência brasileira. In: MOTTA, J. (Coord.). et.al. Cultura organizacional e cultura brasileira . São Paulo: Atlas, 1997.

THOMPSON, J. B. Ideologia e Cultura Moderna: teoria social crítica na era dos meios de comunicação de massa. Petrópolis/RJ: Vozes, 1995.

VIDIGAL, A.C.Viva a empresa familiar. Rio de Janeiro : Rocco, 1996.

VIDIGAL, A.C. As origens da empresa familiar no Brasil. In: MARTINS, J.G. (Coord.) et. al. Empresas familiares brasileiras: perfil e perspectivas. São Paulo: Negócio Editora, 1999.

Kátia Barbosa Macedo é Professora dos departamentos de Administração e Psicologia, nível de Graduação e Mestrado da Universidade Católica de Goiás, Doutora em Psicologia social pela PUC-SP. O endereço eletrônico da autora é: katia.Macedo@cultura.com.br

Cássia Maria Moura Caixeta é Professora do departamento de Direito da Universidade Salgado de Oliveira, Mestre em Psicologia pela UCG. O endereço eletrônico da autora é: cassiacaixeta@ig.com.br

Daniela Cristina Guimarães é Mestre em Psicologia pela UCG. O endereço eletrônico da autora é: dcguimaraes@hotmail.com

Goiacira Nascimento Segurado Macedo é Professora de Psicologia da Faculdade Ávila, Mestre em Psicologia pela UCG. O endereço eletrônico da autora é: ciramacedo@ig.com.br

Janete Capel Hernande é Professora do departamento de Administração e Educação da
Universidade Salgado de Oliveira, Mestre em Psicologia pela UCG. O endereço eletrônico da autora é: janetecapel@ig.com.br

Kátia Barbosa Macêdo, Cássia Maria Moura Caixeta, Daniela Cristina Guimarães, Goiacira Nascimento Segurado e Janete Capel Hernandez. O processo sucessório em organizações familiares e a exclusão da mulher. Recebido: 22/04/2004 $1^{\text {a }}$ revisão: 23/06/2004 $2^{a}$ revisão: 13/09/2004 $3^{\text {a }}$ revisão: 29/09/2004 Aceite final: 5/10/2004 